\title{
The Subsidy-Based Solar Energy Policy in Taiwan
}

\author{
Jin-Li Hu ${ }^{*}, 1$ Jui-Chu Lin ${ }^{2}$, Tzu-Cheng Yang ${ }^{1}$ and Meng-Chi Chi ${ }^{1}$ \\ ${ }^{1}$ Institute of Business and Management, National Chiao Tung University, Taiwan \\ ${ }^{2}$ General Education Center, National Taiwan University of Science and Technology, Taiwan
}

\begin{abstract}
There are five major factors affecting the adoption of renewable energy for the households in Taiwan: price, environmental consciousness, education, geography, and building density. However, although people usually tend to be environment-friendly, the price is still the major concern for households in considering the adoption of renewable energy equipments. Therefore, subsidies have become the major policy instrument to promote household installation of renewable energy devices. This study takes the case of the solar water heaters (SWHs) as an example of how Taiwan subsidizes households to adopt renewable energy equipments.
\end{abstract}

Keywords: Renewable energy, subsidies, solar water heaters.

\section{INTRODUCTION}

Since the 1973 energy crisis, countries all over the world have realized the importance of energy to national security as well as economic development. Moreover, greenhouse gases produced by energy consumption have drastic impacts on global climate change, which attracts attention and efforts under the UN Framework Convention on Climate Change.

Taiwan's dependence on imported energy rated up to $99.32 \%$ in 2008 [6]. The cost of imported energy accounts for $11.31 \%$ of Taiwan's GDP [1]. In the face of constant rise of energy prices, the heavy cost of imported energy impacts not only household expenditures, but also the island's overall economic growth [15]. The $66.32 \%$ and $24.89 \%$ of imported energy are coal and petroleum, respectively. The Kyoto Protocol has been effective since February 16, 2005. Although Taiwan is not a UN member such that it cannot sign the Kyoto Protocol, Taiwan has shown its resolution fulfill the international obligations of $\mathrm{CO} 2$ emission reduction. Especially, Taiwan's carbon emission was 0.27 billion tons in 2006 , accounting for $0.97 \%$ in the global carbon emission, ranking the 22nd highest in the world [21]. The per capita carbon emission is as high as 11.87 tons, about three times of the world's average (4.4 tons).

Comparing to other economies with similar per capita GDP, Taiwan's per capita CO2 emission is only secondary to that of Saudi Arab (Table 1). Comparing to thirty advanced economies, ${ }^{1}$ Taiwan's per capita carbon emission

*Address correspondence to this author at the 118, Sec. 1, Chung-Hsiao W. Rd., Taipei City 100, Taiwan; Fax: +886-2-23494922;

Email: jinlihu@yahoo.com

\footnotetext{
1 There are thirty advanced economies/countries in the International Monetary Fund (IMF) web site (April, 2007), including Australia, Austria, Belgium, Canada, Cyprus, Denmark, Finland, France, Germany, Greece, Hong Kong SAR, Iceland, Ireland, Israel, Italy, Japan, Republic of Korea, Luxembourg, Netherlands, New Zealand, Norway, Portugal, Singapore, Slovenia, Spain, Sweden, Switzerland, Taiwan, United Kingdom, and United States.
}

is ranked to seven among these advanced economies and only next to Singapore in the Asian advanced economies (12.8294 metric tons per capita). Taiwan is facing an imminent task to cope with climate change. As a result, renewable energy is one of the major policy instruments for Taiwan to reduce its imported energy dependence as well as to reduce its per capita carbon emission [16].

The use of renewable energy can help promote energy technologies, reduce $\mathrm{CO}_{2}$ emission and imported energy dependence of an economy $[15,16]$. Situated in the subtropical and tropical areas, Taiwan is blessed with long sunshine hours over the year. Except for a few places, most parts of Taiwan have average sunshine hours of 1,500 to 2,200 hours per year. In Southern Taiwan, some places such as Tainan and Hengchun even have annual sunshine of up to 2,300 hours (Table 2). The daily solar energy per square meters is around 3,000 to 4,300 thousand calories, making Taiwan a suitable place for the development of the solar energy industries [13, 21, 31, 38].

Taiwan has passed the Renewable Energy Development Act in June 2009, using guaranteed prices to purchase electricity generated by renewable energy sources which includes the solar power [26, 34]. The Bureau of Energy has published the 2010 renewal energy wholesale purchase rates and formulas on January 25, 2010, according to Article 9 in the Renewable Energy Development Act (see Table 3).

\section{TAIWAN'S SOLAR HEATER PROMOTION PROGRAM}

In order to cope with the impacts of global climate change on Taiwan, renewable energy sources have been promoted, among which the development of solar energy is growing steadily over the last seven years (Fig. 1).

Taiwan imported the foreign-made solar heaters in the 1973 energy crisis. In order to promote the solar energy application, increase domestic energy supply, and save traditional energy consumption, the government has been 
Table 1. Taiwan's Carbon Emission - A Comparison with Similar GDP Per Capita Countries in 2006

\begin{tabular}{|c|c|c|c|c|c|c|}
\hline Country & $\begin{array}{c}\text { GDP Per } \\
\text { Capita } \\
\text { (U.S. Dollars) }\end{array}$ & $\begin{array}{c}\text { Carbon Emissions } \\
\text { Per Capita } \\
\text { (Metric Ton) }\end{array}$ & $\begin{array}{c}\text { Annual Carbon } \\
\text { Emissions (Thousands } \\
\text { of Metric Tons) }\end{array}$ & $\begin{array}{c}\text { Percentage of } \\
\text { Global Total } \\
\text { Emissions }\end{array}$ & $\begin{array}{c}\text { Global Rank of } \\
\text { Carbon Emissions } \\
\text { Per Capita }\end{array}$ & $\begin{array}{c}\text { Global Rank of } \\
\text { Annual Carbon } \\
\text { Emissions }\end{array}$ \\
\hline \hline Czech & $13,863.89$ & 11.27 & 116,991 & $0.4 \%$ & 26 & 34 \\
\hline Saudi Arabia & $15,049.62$ & 15.78 & 381,564 & $1.3 \%$ & 14 & 15 \\
\hline Malta & $15,805.23$ & 6.2961 & 2,556 & $0.01 \%$ & 63 & 133 \\
\hline Taiwan & $\mathbf{1 5 , 9 7 7 . 5 3}$ & $\mathbf{1 1 . 8 7}$ & $\mathbf{2 7 4 , 3 6 6}$ & $\mathbf{0 . 9 7} \mathbf{1 0}$ & $\mathbf{2 2}$ \\
\hline South Korea & $18,395.34$ & 9.89 & 475,248 & $1.7 \%$ & & 35 \\
\hline
\end{tabular}

Data source: $[25,37]$.

Table 2. The Average Annual Sunshine Hours of Major Areas in Taiwan from 1971 to 2000

\begin{tabular}{|c|c|c|c|c|c|c|}
\hline & Taipei & Tainan & Kaohsiung & Taichung & Hengchun & Taitung \\
\hline Average annual sunshine hours & $1,408.3$ & $2,263.7$ & $2,081.6$ & $2,084.8$ & $2,303.6$ & $1,731.5$ \\
\hline
\end{tabular}

Data source: [7].

Table 3. The Wholesale Purchase Rates of Various Renewable Energy Sources

\begin{tabular}{|l|c|}
\hline \multicolumn{1}{|c|}{ Type } & Rate (NTD/Kwh) \\
\hline \hline 1-10 Kwh Photovoltaic & 11.1883 \\
\hline 10-500 KWh Photovoltaic & 12.9722 \\
\hline 500- Photovoltaic & 11.1190 \\
\hline 1-10 Kwh Wind power & 7.2714 \\
\hline 10- Wind power & 2.3834 \\
\hline Offshore wind power & 4.1982 \\
\hline Run-of-the-river hydroelectricity & 2.0615 \\
\hline Terrestrial heat & 5.1838 \\
\hline Biomass & 2.0615 \\
\hline Waste & 2.0879 \\
\hline Others & 2.0615 \\
\hline
\end{tabular}

Note: NTD is the abbreviation for the New Taiwan dollar.

Data source: [35].

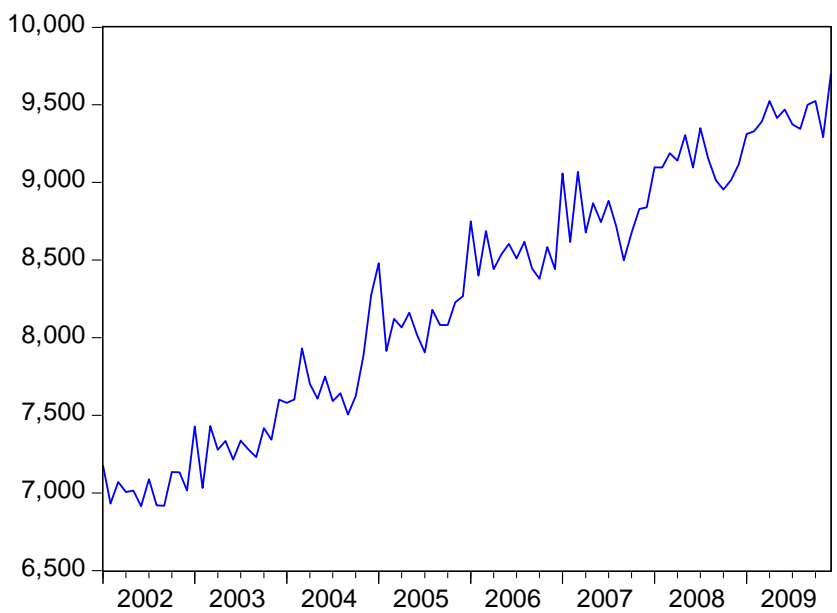

implementing programs to transfer technology and encourage the installation of solar heaters. In Taiwan, the promotion of solar energy has been relying on incentive measures such as subsidies, which are mainly in the form of projects. In 1986 the Energy Commission (which now becomes the Bureau of Energy) released the First-stage Regulations of Promoting and Rewarding Solar Heater Systems. This regulation computes the subsidies based on the effective areas of solar energy collection. It was enforced for six and half years until 1992; however, the latter half period is an extension with half of the subsidy rate (see Table 4).

The first-stage program from 1986 to 1992 effectively induced the trend to install and use solar heaters, helping the solar energy industrial development. However, since 1995 there was a decline in the construction and estate industries, making the demand for solar heaters also drop. In order to cope with the impacts of UN Framework Convention on the Climate Change and help develop the renewable energy industries, the National Energy Conference held in May 1998 concluded new subsidy and reward measures toward solar heaters. Following this resolution, the Bureau of Energy released the Second-stage Regulations of Promoting and Rewarding Solar Heater Systems.

The second program ran from January 2000 to December $2004[11,29]$. As listed in Table 5, the subsidy criteria were made in accordance with the types of solar heaters, the effective solar energy collection area, and the islands (the Taiwan Island and the off-shore islands) on which the solar heaters were located.

In order to reduce the impacts of global financial crisis on domestic consumption, on September 11, 2009 the Meeting of Executive Yuan passed the Project of Dealing with Business Cycle and Promoting the Economy, which includes the subsidies of solar heaters and photovoltaic systems. Therefore, Taiwan revised the previous subsidy standards (Table 5) in January 2009, and increased the subsidy rates (Table 6).

Fig. (1). The solar energy consumption in Taiwan from 2002 to 2009. 
Table 4. The Subsidy Standards for Solar Heater Installment in Taiwan from 1986 to 1992

\begin{tabular}{|c|c|c|c|c|}
\hline Types & Metal Type & Non-Metal Type & Integral Collector-Storage Type & Unglazed Type \\
\hline \hline $1986-1989$ & NTD $2,000 / \mathrm{m}^{2}$ & NTD $1,500 / \mathrm{m}^{2}$ & NTD $1,500 / \mathrm{m}^{2}$ & $\mathrm{NTD} 1,000 / \mathrm{m}^{2}$ \\
\hline 1990- June,1992 & NTD $1,000 / \mathrm{m}^{2}$ & NTD $800 / \mathrm{m}^{2}$ & $\mathrm{NTD} 800 / \mathrm{m}^{2}$ & $\mathrm{NTD} 500 / \mathrm{m}^{2}$ \\
\hline
\end{tabular}

Data source: [11].

Table 5. The Subsidy Standards for Solar Heater Installment in Taiwan in 2000

\begin{tabular}{|c|c|}
\hline Taiwan Island & Subsidy Rate \\
\hline \hline Cover plate type & NTD $1,500 / \mathrm{m}^{2}$ \\
\hline Vacuum tube type & NTD $1,500 / \mathrm{m}^{2}$ \\
\hline Non-cover plate type & NTD $1,000 / \mathrm{m}^{2}$ \\
\hline Other types & Decided by the authorities \\
\hline Off-Shore Islands & Subsidy Rate \\
\hline \hline Cover plate type & NTD $3,000 / \mathrm{m}^{2}$ \\
\hline Vacuum tube type & NTD $3,000 / \mathrm{m}^{2}$ \\
\hline Non-cover plate type & NTD $2,500 / \mathrm{m}^{2}$ \\
\hline Other types & Decided by the authorities \\
\hline
\end{tabular}

\section{AN OVERVIEW ON THE SOLAR HEATER PROMOTION PROGRAM}

In Taiwan, the supply of renewable energy in 2009 is $548,368 \mathrm{KL}$ oil equivalents, which is $5.1 \%$ less than the previous year's level. Solar energy accounts for only $0.08 \%$ of the total energy supply in Taiwan [3]. Currently, solarheating amounts to almost all the consumption of solar energy in Taiwan. Therefore, an analysis of the solar water heater promotion is a good proxy for the solar energy usage in Taiwan.

As mentioned above, Taiwan implemented its second project from 2000 to 2004, in order to encourage the use of solar water heaters by subsidizing the installation of them.
Table 7 shows that after this subsidy program ceased at the end of 2004. Since the government implements these incentive programs, in the previous half period (2000-2002) there were significant increases in the installment areas of solar heaters. There is a recovery in the construction and estate industries since 2002, further boosting up the solar heater area. However, due to the economic recession the number of new installments then grew slowly. In 2007 the newly installed area of solar heaters even declined, compared to the year 2006. In order to further stimulate the growth of installed area for solar heaters, the Third-stage Regulations of Promoting and Rewarding Solar Heater Systems was announced in 2009.

Table 6. The Subsidy Standards for Solar Heater Installment in Taiwan in 2009

\begin{tabular}{|c|c|}
\hline Taiwan Island & Subsidy Rate \\
\hline \hline Cover plate type & NTD $2,250 / \mathrm{m}^{2}$ \\
\hline Vacuum tube type & NTD $2,250 / \mathrm{m}^{2}$ \\
\hline Non-cover plate type & NTD $1,500 / \mathrm{m}^{2}$ \\
\hline Other types & Decided by the authorities \\
\hline Off-Shore Islands & Subsidy Rate \\
\hline \hline Cover plate type & NTD $4,500 / \mathrm{m}^{2}$ \\
\hline Vacuum tube type & NTD $4,500 / \mathrm{m}^{2}$ \\
\hline Non-cover plate type & NTD $3,750 / \mathrm{m}^{2}$ \\
\hline Other types & Decided by the authorities \\
\hline
\end{tabular}

Data source: [30].

Table 7. The New Applications and Increased Subsidized Areas from 2000 to 2007

\begin{tabular}{|c|c|c|c|c|}
\hline Year & $\begin{array}{c}\text { Number of New } \\
\text { Applications }\end{array}$ & $\begin{array}{c}\text { Growth Rate of } \\
\text { New Applications (\%) }\end{array}$ & $\begin{array}{c}\text { Increased Subsidized } \\
\text { Area Each Year (m) }\end{array}$ & $\begin{array}{c}\text { Growth Rate of Increased } \\
\text { Subsidized Area (\%) }\end{array}$ \\
\hline \hline 2000 & 6,659 & - & 25,908 & - \\
\hline 2001 & 13,526 & 103.12 & 70,029 & 170.30 \\
\hline 2002 & 14,693 & 8.63 & 70,986 & 7.37 \\
\hline 2003 & 16,548 & 12.63 & 77,753 & 27.60 \\
\hline 2004 & 21,662 & 30.90 & 99,215 & 10.40 \\
\hline 2005 & 22,587 & 4.27 & 109,536 & 4.45 \\
\hline 2006 & 24,398 & 7.62 & 114,413 & 114,694 \\
\hline 2007 & 24,332 & -0.27 & - & 0.245 \\
\hline 2008 & 24,518 & 0.76 & & - \\
\hline
\end{tabular}


Since the first-stage Regulations of Promoting and Rewarding Solar Heater Systems in 1986 till the third-stage project effective in 2009, the government has subsidized 180,675 installments till the end of 2009, accounting for 900,054 square meters of solar heat collection. The coverplate type is the major solar heater type, accounting for $93 \%$ of all solar heaters in Taiwan. The vacuum-tube type accounts for another $6 \%$ and has been increasing in share due to its advantage of lower price. According to a report published by the Bureau of Energy, Taiwan already has 470,000 households with solar water heaters, accounting for $6 \%$ of the 7,794,786 households in total, is number one in Asia and number three in the world (only next to Israel and Cyprus). Eighty percent of Taiwan's solar water heaters are installed in the central (29\%) and southern (54\%) areas. In Nantou County, which was seriously stricken by the earthquake on September 21, 1999, most of the rebuilt houses are now equipped with the solar water heater system, ranking the number one in terms of density in Taiwan [17].

It is estimated that, comparing to liquid gas, a solar water heater system can on average save 7,600 NTD for a household, making the cost recovery period as short as three years. Moreover, each squared meters of solar water heater system can replace $150 \mathrm{Kg}$ standard coals, $80 \mathrm{~L}$ petroleum, $60 \mathrm{Kg}$ liquid gas, and $220 \mathrm{Kg} \mathrm{CO} \mathrm{CO}_{2}$ per year, which is equivalent to 417 Watt-hours, reducing $4.85 \mathrm{Kg}$ of $\mathrm{SO}_{2}$ emission, $2.2 \mathrm{Kg}$ of $\mathrm{NO}_{2}$, and $3.75 \mathrm{Kg}$ of dust [33]. There are about 26,000 new users of solar heaters per year in Taiwan, accounting for extra saving $10,000 \mathrm{KL}$ petroleum, 7,500 tons liquid gas, and 27,000 tons of $\mathrm{CO}_{2}$ emission in each year. It is estimated that the installed solar water heaters in Taiwan total can annually save 5.3 million barrels of $20 \mathrm{Kg}$ liquid gas and reduce 380,000 tons of $\mathrm{CO} 2$ emission as 0.1357 percent of Taiwan's total annual emission $[2,11]$.

\section{KEY SUCCESS FACTORS OF THE SOLAR WATER HEATER PROMOTION IN TAIWAN}

The five key success factors of the solar water heater promotion in Taiwan can be summarized by the conceptual framework depicted by Fig. (2) $[8,10,18,27]$. These success factors will determine the consumer's decision whether or not to purchase a solar water heater device. These success factors hence need to be improved, in order to promote the overall use of solar energy in Taiwan.

Fig. (2) can be followed by brief discussions:

1. Price: The installment cost of a solar water heater device is much higher than a liquid gas-fueled one. The price has been a major barrier for consumers in Taiwan to choose a solar water heater. Price responses may play a crucial role in affecting income and energy consumption in highly energy-dependent economies $[19,23]$. Changes in prices seem to cause changes in income and energy in the case of Taiwan. It is the rate of price change that leads the change in energy consumption [28]. Furthermore, the use of government tax credits and subsidies for the production and use of sustainable alternative energy sources may provide the needed incentive for both producers and consumers to substitute away from coal to more sustainable energy sources over time [5]. These are the reasons why subsidies are widely used to promote the use of solar energy. On the other hand,

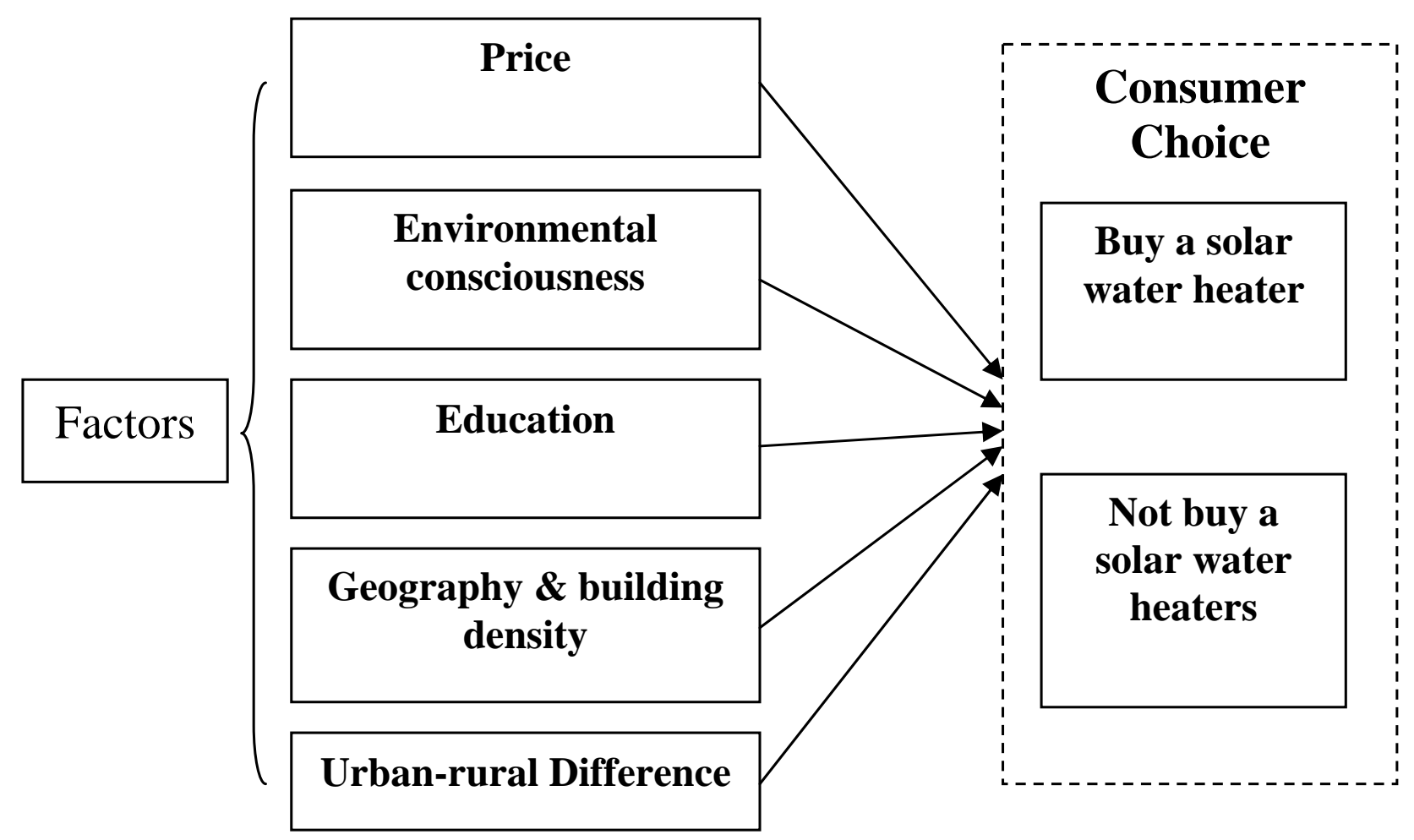

Fig. (2). Factors of the Consumer Choice for a Solar Water Heater. 
the sustainability of renewable energy development must depend on both the impacts of energy prices and the level of GDP growth [12]. Taiwan has much lower energy prices (e.g., petroleum and liquid gas) than neighbor economies (as shown in Fig. 3), hence hindering the promotion of solar heaters. That is, there are significantly substitution effects among the energy sources in Taiwan and low prices of nonrenewable will hence lower the incentive to use solar energy.

NTD/L

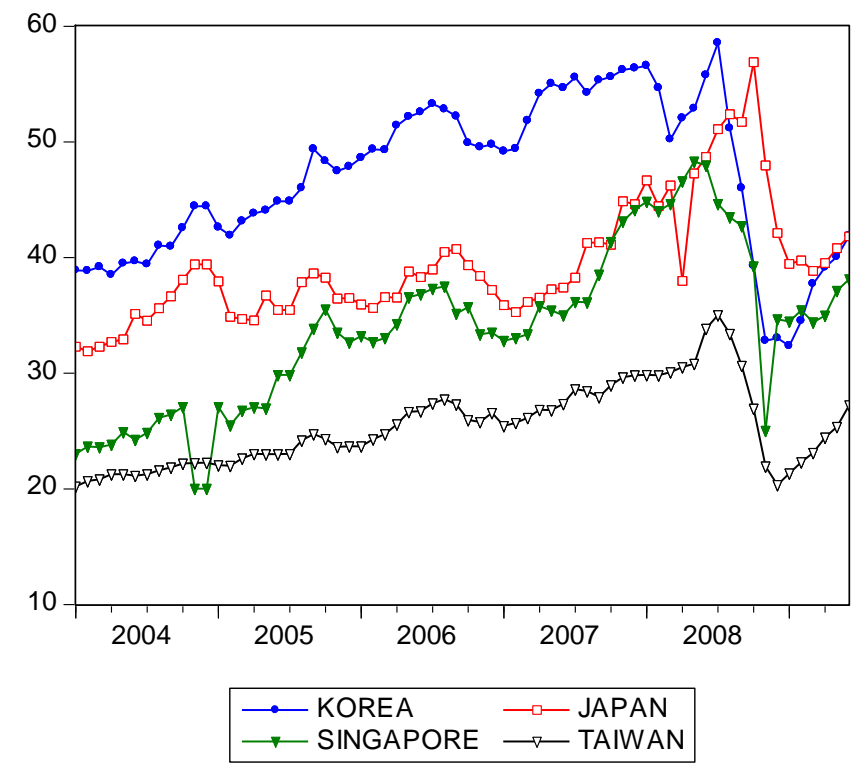

Fig. (3). The monthly 92 leadless gasoline prices of Taiwan and neighbor economies. Data Source: [6].

2. Environmental consciousness: An environmentally conscious consumer is more likely to choose a solar water heater device, in order to save petro-fossil fuels and to reduce greenhouse gas emissions.

3. Education: The authorities should educate consumers by providing more information about the advantages of solar energy and the incentive measures available to them in purchasing solar-powered devices.

4. Geographical condition: The installment of solar energy device takes space and needs a longer timespan of sunshine. With longer sunshine hours and lower population density, the central and Southern parts of Taiwan are more suitable for the application of solar energy than the North.

5. Urban-rural difference: Most of the population in Taiwan is in the urban areas. Northern Taiwan has much higher building density than the central and southern areas, hindering the installment of solar energy device. Although the rural areas have better conditions for solar devices, it has much less population and fewer households, hence reducing the demand for these equipments.

\section{CONCLUDING REMARKS}

As has been demonstrated, incentive measures have played an essential role for the promotion of solar-powered devices in Taiwan. For example, in September 2008 the Kaohsiung City Government announced that it would further provide additional subsidies for solar heaters (Table 8) and then the installment rate increased for $33 \%$. There has been more than 20,000 solar heater installments since 2001, making Kaohsiung City have the most installments in Taiwan [36].

Table 8. The Extra Subsidy Standards for SWHs Installment of Kaohsiung City in 2008

\begin{tabular}{|c|c|}
\hline Types & Subsidy Rate \\
\hline \hline Cover plate type & NTD $2,250 / \mathrm{m}^{2}$ \\
\hline Vacuum tube type & NTD $2,250 / \mathrm{m}^{2}$ \\
\hline Non-cover plate type & NTD $1,500 / \mathrm{m}^{2}$ \\
\hline Other types & Decided by the authorities \\
\hline Data source: $[22]$.
\end{tabular}

Data source: [22]

However, public subsidies could increase government expense and budget deficit, distort the price-setting mechanism, and violate the 'user-pay' principle. The costdown strategy via innovation and refinement from the supply side can be an alternative for the subsidy instruments. The preferential loan is also a feasible measure to promote the use of clean energy. According to the Second-Stage Rules of Preferential Loan for Purchasing Clean Energy Equipment [31], there have been preferential loans to enterprises and households to adopt solar energy. Most of the solar heater users till now are still households. The recovery period for the setup cost of a solar heater is about three years. Compared to direct subsidies, preferential loans make the users pay more but still provide incentive. Preferential loans may be relatively fair than direct subsidies and can ease the government's deficit. Moreover, the development of the solar energy industry in Taiwan can also provide employment opportunity and promote export.

The domestic market of solar energy can be boosted by both consumer purchases and government procurements. Education can effectively promote consumers' environmental consciousness and hence change people's behavior. Local authorities can also work with communities to promote public awareness and household use of green energy. In July 2009 the Penghu County, a series of smaller islands in the Taiwan Strait, planed to become a county of low carbon emission. The target is to have its renewable energy ratio no less than $50 \%$ by utilizing solar energy and wind power, etc. [14]. The effective demand for green energy by both private and public sectors is the deterministic force in promoting its development in Taiwan.

\section{ACKNOWLEDGEMENT}

Partial financial support from Taiwan's National Science Council (NSC-98-2410-H-09-055) is gratefully acknowledged.

\section{REFERENCES}

[1] 2007 Energy Statistics Handbook. Bureau of Energy 2007.

[2] 2007 Annual Report. Bureau of Energy 2008.

[3] 2009 Energy Stat. Monthly Report. Bureau of Energy 2009. Available from: http://www.moeaboe.gov.tw/opengovinfo/Plan/all/ energy_mthreport/main 
[4] 2009 National Energy Conference Resolutions. Bureau of Energy 2009. Available from: http://www.moeaboe.gov.tw/Policy/98Ener gyMeeting/MeetingMain.aspx?pageid=convention

[5] Apergis N, Payne JE. Coal consumption and economic growth: Evidence from a panel of OECD countries. Energy Policy 2010; 38(3): 1353-1359.

[6] Bureau of Energy 2009. Available from: http://www.moeaec.gov. tw

[7] Central Weather Bureau 2010. Available from: http://www.cwb. gov.tw/eng/index.htm

[8] Chandler KMM, Crown EM, Brown SA. Consumer information and education effects on knowledge and choice of fire resistant upholstery. J Consu Affairs 1991; 17: 81-106.

[9] Chang KC, Lee, TS, Chung KM. Solar water heaters in Taiwan. Renewable Energy 2006; 31(9): 1299-1308.

[10] Chang KC, Lee TS, Lin WM, et al. Outlook for solar water heaters in Taiwan. Energy Policy 2008; 36: 66-72.

[11] Chang KC, Lee TS, Chung KM, et al. The effects of promoting solar heaters on energy savings and carbon reduction. Environmental Protection Source 2008; 125. Available from: http://www.fengtay.org.tw/paper.asp?page $=2008 \&$ num $=1065 \&$ nu $\mathrm{m} 2=143$

[12] Chang TH, Huang CM, Lee MC. Threshold effect of the economic growth rate on the renewable energy development from a change in energy price: Evidence from OECD countries. Energy Policy 2009; 37(12): 5796-5802.

[13] Chen TY, Yu OS, Hsu GJY, et al. Renewable energy technology portfolio planning with scenario analysis: a case study for Taiwan. Energy Policy 2009; 37: 2900-2906.

[14] Chiang HC, Hung JC, Chen YC. Penghu wants to be low-carbon islands with fifty percent of renewable energy. China Times, July 19, 2009. Available from: http://www.phsea.com.tw/phseaforum/ posts/list/26709.page

[15] Chien TC, Hu JL. Renewable energy and macroeconomic efficiency of OECD and non-OECD economies. Energy Policy 2007; 35: 3606-3615.

[16] Chien TC, Hu JL. Renewable energy: An efficient mechanism to improve GDP. Energy Policy 2008; 36: 3045-3052.

[17] Chu WN, Miao CP, Lee HC, et al. The solar water heater density is heading toward number one in the world. United Daily News, May 4, 2009. Available from: http://www.dost.com.tw/news_detail. asp?NewsId=139

[18] Consumer Guide to Home Energy Savings: Condensed Online Version. American Council for an Energy Efficient Economy 2007. Available from: http://www.aceee.org/consumerguide/waterheating. htm

[19] Dunkerley J. Estimation of energy demand: the developing countries. Energy J 1982; 3: 79-99.

[20] Energy Briefing. Bureau of Energy 2008. Available from: http://www.moeaboe.gov.tw/About/webpage/index.htm

[21] Energy Statistics Interim Reports. Bureau of Energy 2009.

[22] Environmental Protection Administration. Available from: http://ecolife.epa.gov.tw
[23] Hoa TV. A multi-equation model of energy consumption in Thailand. Int J Energy Res 1992; 16: 381-385.

[24] Hoa TV. Effects of oil on output growth and inflation in developing countries: the case of Thailand from January 1966 to January 1991 Int J Energy Res 1993; 17: 29-33.

[25] International Monetary Fund. Available from: http://www.imf.org/ external

[26] Laws and Regulations Database of Taiwan. Available from: http://law.moj.gov.tw

[27] Lenzen M, Dey CJ. Economic, energy and greenhouse emissions impacts of some consumer choice, technology and government outlay options. Energy Economics 2002; 24: 377-403.

[28] Masih AMM, Masih R. On the temporal causal relationship between energy consumption, real income, and prices: some new evidence from Asian-energy dependent NICs based on a multivariate cointegration/vector error-correction approach. Journal of Policy Modeling 1997; 19(4): 417-440.

[29] Regulations of Promoting and Rewarding Solar Heater Systems Bureau of Energy 2000. Available from: http:/www.moeaboe.gov. tw/opengovinfo/Laws/secondaryenergy/LSecondaryMain.aspx?Pag eId=1_secondary_list

[30] Regulations of Promoting and Rewarding Solar Heater Systems. Bureau of Energy 2009. Available from: http://www.moeaboe. gov.tw/opengovinfo/Laws/secondaryenergy/LSecondaryMain.aspx ?PageId=1_secondary_list

[31] Revised Second-Stage Rules of Preferential Loan for Purchasing Clean Energy Equipment. Bureau of Energy 1999. Available from: http://www.moeaboe.gov.tw/opengovinfo/Laws/saveenergy/LSave Main.aspx?PageId=1_save_10

[32] Solar Technology Research Program. Bureau of Energy 1999.

[33] Sun SC. The solar water heaters are out in the policy promoting home electronics to the countryside. China Financial and Economic News, February 26, 2009. Available from: http://homea.people. com.cn/BIG5/41391/8876478.html

[34] Tang PJ. The purchase prices of renewable energy are expected to be stipulated in October. Central News, Agency August 17, 2009 Available from: http://tw.stock.yahoo.com/news_content/url/d/a 090817/1/1mth9.html

[35] The 2010 renewal energy wholesale purchase rates and formulas. Bureau of Energy 2010. Available from: http://www.moeaec. gov.tw/opengovinfo/Laws/secondaryenergy/LSecondaryMain.aspx ?PageId=1_secondary_16

[36] Tsen YS. Kaohsiung City has the most solar heater installment area. Central News Agency, January 22, 2010. Available from: http://www.cna.com.tw/SearchNews/doDetail.aspx?id=201001220 $129 \& \mathrm{q}=\%$ e $9 \%$ ab $\% 98 \%$ e $9 \% 9 \mathrm{~b} \% 84+\%$ e5\%a4\%aa\%e $\% \% 99 \%$ bd

[37] United Nations site for the MDG Indicators. Available from: http://mdgs.un.org/unsd/mdg/Default.aspx

[38] Yue CD, Wang SS. GIS-based evaluation of multifarious local renewable energy sources: a case study of the Chigu area of southwestern Taiwan. Energy Policy 2006; 34: 730-742.

(C) Hu et al.; Licensee Bentham Open.

This is an open access article licensed under the terms of the Creative Commons Attribution Non-Commercial License (http://creativecommons.org/licenses/by$\mathrm{nc} / 3.0 /$ ) which permits unrestricted, non-commercial use, distribution and reproduction in any medium, provided the work is properly cited. 